University of Nebraska - Lincoln

DigitalCommons@University of Nebraska - Lincoln

Communication Studies Theses, Dissertations, and Student Research

$5-2010$

\title{
YouTube Politics: YouChoose and Leadership Rhetoric during the 2008 Election
}

Scott H. Church

University of Nebraska-Lincoln, scott@huskers.unl.edu

Follow this and additional works at: https://digitalcommons.unl.edu/commstuddiss

Part of the Communication Commons

Church, Scott H., "YouTube Politics: YouChoose and Leadership Rhetoric during the 2008 Election" (2010). Communication Studies Theses, Dissertations, and Student Research. 10.

https://digitalcommons.unl.edu/commstuddiss/10

This Article is brought to you for free and open access by the Communication Studies, Department of at DigitalCommons@University of Nebraska - Lincoln. It has been accepted for inclusion in Communication Studies Theses, Dissertations, and Student Research by an authorized administrator of DigitalCommons@University of Nebraska - Lincoln. 
Published in Journal of Information Technology \& Politics 7 (2010), pp. 124-142; doi: 10.1080/19331681003748933

Copyright ( $\odot$ Taylor \& Francis Group, LLC. Used by permission.

Published online May 17, 2010.

\title{
YouTube Politics: YouChoose and Leadership Rhetoric during the 2008 Election
}

\author{
Scott H. Church \\ University of Nebraska-Lincoln
}

\begin{abstract}
The present study employs both qualitative and quantitative research methods to examine the discourse of leadership in the YouTube video clips of 16 candidates who competed in the 2008 U.S. presidential race. The introduction and farewell videos of the candidates included on the YouChoose portion of YouTube are inductively analyzed for leadership utterances. Common categories are constructed through a grounded theory approach, while frequencies of the appearance of leadership traits are discovered through a content analysis of the data. The findings are then compared with relevant literature to determine the nature of presidential campaigns within the participatory culture of YouTube. The study suggests that the YouChoose videos favor the candidate's character over political experience and explores the possibility that the medium promotes passive (rather than active) political engagement on the part of the user. The idea of the construction of the YouTube audience as a "postmodern constituency" is also proposed. Finally, the implications of the study are discussed.
\end{abstract}

Keywords: content analysis, grounded theory, leadership discourse, postmodern, 2008 presidential election, rhetoric, YouTube

In his seminal book Understanding Media, Marshall McLuhan (1994) taught the familiar adage "the medium is the message," indicating that the content of the message is of secondary importance to the way it is presented. Similarly, Benjamin Page (1996) wrote that "public deliberation is highly mediated" (p. 106), wherein print media provide democratic societies with important vehicles for disseminating political information. As a direct fulfillment of these innovative statements, the Web site YouTube.com (hereafter, YouTube) has emerged to become a site of robust appeal in the attempt to mobilize the political interests of young citizens (McKinney \& Rill, 2009). Though the messages presented on the Web site are often banal and far from revolutionary, YouTube has moved on the digital continuum from obscurity to increasing political relevance (Collins, 2006; Fernandez, 2006; Grossman, 2006). Given the recent reiterative finding that "media exposure does, in fact, affect politically relevant attitudes, and ... these effects differ markedly by media type" (Overby \& Barth, 2009, p. 286), YouTube should be considered as an emerging credible outlet of political discourse.

Scott H. Church (B.A., Brigham Young University, M.A., Southern Utah University) is a doctoral student at the University of Nebraska-Lincoln. The author wishes to thank Dr. Kevin Stein for his encouragement and help during the research and writing process. Thanks also to Dr. Suzanne Larson, Dr. Matthew Barton, and Heather Church for their ideas and feedback. Finally, the author thanks with much gratitude Dr. Michael Xenos and Dr. Stuart Shulman as well as the anonymous reviewers for Journal of Information Technology E Politics for their helpful suggestions.

Correspondence: Scott H. Church, Department of Communication Studies, University of Nebraska-Lincoln, 417 Oldfather Hall, Lincoln, NE 68588; email scott@huskers.unl.edu 


\section{Youtube as a Political Forum}

In July of 2007, YouTube was brought to the country's attention for its connection to the presidential candidate debates (McKinney \& Rill, 2009). In addition to its already extensive coverage in the nation's media for its entertaining- yetamateur video clips, it was now being lauded for its decision to dedicate a portion of the Web site to "YouChoose," a viral forum for presidential candidates to campaign in the digital sphere. This new forum not only facilitated the extension of other media's coverage of the candidates to the Internet, it also provided the means for the candidates to delineate their platforms in an appealing way to the wired generation. This was an important opportunity for presidential candidates, given YouTube's emerging legacy as a vehicle for political accountability: It has been suggested that in the 2006 nationwide Senate elections, at least two candidates lost as a result of uncomplimentary clips posted on YouTube (Tan, 2007). The Web site likewise played a significant role in the U.S. elections of 2006 with its proliferation of amateur videos documenting campaign speeches along with questionable comments and actions of political candidates (Fernandez, 2006; Poniewozik, 2006b). YouChoose, however, provided a venue for presidential candidates and their campaigns to exclusively upload videos officially sanctioned by each candidate. In this way, YouChoose added an effective ethos to the grassroots site by changing it from a space of vernacular "bottom-up" credibility to a legitimate space of "top-down" political discourse.

In sum, mediated politics have begun to assume a new appearance on YouChoose. Like the Internet, it has not only "empowered ordinary citizens to become engaged, active and highly influential participants in democracy" (Fernandez, 2006, p. A19), but it has also empowered political candidates to upload their own campaign videos to a site expressly created for this purpose. Due to the media- and technology-saturated political atmosphere of recent public discourse, as well as the relatively recent popularity of YouTube in the public sphere, an analysis of the political discourse on YouTube is warranted. This study will inductively examine these mediated political messages for their common rhetorical leadership strategies. In turn, the frequencies of these particular utterances coupled with the unique form of the medium will yield insights on the nature of a potential new breed of politics called "YouTube Politics."

\section{Mediated Deliberation and Rhetorical Strategies in Public Discourse}

Because of the relative newness of the topic, the corpus of literature about YouTube has been generally limited to magazines, Internet publications, and some trade journals, though the field is quickly growing (see Burgess \& Green, 2009; McKinney \& Rill, 2009). The literature reviewed below examines the Internet as a medium at the intersection of language, culture, and politics; it also observes the role of the Internet in politics and deliberation. The review of these articles will serve as a useful starting point for our subsequent discussion of the nature of discourse and politics on YouTube.

\section{Media and Public Deliberation}

One of the seminal media effects studies of political campaigns was conducted in the early 1940s by sociologists Lazersfeld, Berelson, and Gaudet (1968). In this study, which was conducted to determine the effects of the media upon the political attitudes of media consumers in the public sphere, the researchers concluded that the media, in part, "reinforced the partisan" (p. 101). This finding is especially significant when viewed in the context of the exceedingly partisan blogs that permeate public discourse today. Habermas (1989) also wrote about public deliberation, claiming that the presence of rational- critical debate is crucial to a functioning public sphere. However, he claimed, the proliferation of the media in society has gradually transformed the rational and critical public's interests from debate to the pursuit of leisure and consumption, thus hindering efficacious public deliberation. Incidentally, recent political theorists have updated Habermas's concept of the 
place of mediated deliberation to the digital age, with Dahlgren asserting that the public sphere is now permeated by interactive new media (as cited in Xenos, 2008).

Iyengar and Simon (1993), while eschewing a Habermasian polemic toward the media, still found that the media has a significant impact on public opinion. In their study of political attitudes surrounding the Gulf War, they found that the TV coverage mobilized support for president George H. W. Bush's decision for a military resolution to the conflict. Page (1995) contended that the speed of information dissemination in the digital age has increased, and by so doing has altered the landscape of public deliberation. As an illustration of this claim, when former president Bush's unpopular comments regarding the cause of the Los Angeles riots were rapidly spread to the public via the mass media, a "negative elite consensus" was ignited (p. 259). This negative response to political figures can be manifest through the editorial pages in electronic and print media, both of which Page believed to be strong shapers of public opinion. It should also be noted that the overt political opinions in these editorial pages also pervade ostensibly objective news stories as well (Page, 1996).

"Elite discourse" - the discourse from political actors upon whom the public is largely dependent for its political information - is at the core of public opinion (Simon \& Xenos, 2000, p. 363). This concept is exemplified in a study by Simon and Jerit (2007) in which the researchers traced the discursive differences between "baby" and "fetus" as each was used in the recent partial-birth abortion debate and its subsequent effect upon public opinion. Their research yielded findings suggesting that elite discourse is composed of distinctive vocabularies used to advance the agendas of the elites. These vocabularies, in turn, are appropriated and disseminated by the media, upon which citizens' opinions are often based.

The Internet and its corresponding interactivity may also influence the voting public. It has been argued that the Internet became an integral part of presidential campaigns as early as 1996 when both presidential candidates Bill Clinton and Bob
Dole began using it to communicate with voters (McKeown \& Plowman, 1999). Importantly, during this time, the Internet was beginning to facilitate an escape from the traditional "push" distribution of information of the past, where mass media was "pushing" bits of information at people, to a "pull" distribution, where media consumers were actively searching on their computers to acquire information (Negroponte, 1995, p. 84). Logically, the fact that this information was willingly being accessed because the citizen consumer wanted to read it indicates a progression from only years earlier when individuals were receiving much information distributed only through the major television network gatekeepers. A decade ago, McKeown and Plowman (1999) speculated that the accessibility of the Internet would help it become the preferred way to share political information. Partly because of this, they concluded that candidates used the Internet more than the traditional forms of media, like television. Yoon and Joseph (2008) recently confirmed this assertion in their study, stating that candidates' Web pages are more effective than television advertising at delivering information about that candidate.

Given the interactivity that permeates mediated politics, Barry (2006) has explained that the Internet has become connected to civic engagement: "[I] nteractive and networked technologies have come to be seen as a key resource in the making up of citizens. New technology is reckoned by many to play a critical part in the revitalization of democracy. ... Interactive technology is expected to produce active citizens" (p. 163).

When a viewer sees a political debate on television, he or she has little opportunity to interact. In contrast, however, "while reading a story on the Internet or watching a streaming video of an interview with a journalist or a politician, a citizen can shoot an e-mail off to a federal agency or make a monetary contribution to the politician" (Mayer, 2008, p. 300). Political blogs likewise present a medium for interactive deliberation in the public sphere (Xenos, 2008). This interactivity between the Internet and the informed citizen lies at the core of the political success of YouTube. 


\section{Leadership Utterances and Rhetorical Strategies}

Studies have been conducted that research each candidate's references to leadership in a variety of contexts. An influential analytic approach to the use of language in campaigns was proposed in the form of Benoit's functional theory of political campaign discourse (Benoit, Stein, \& Hansen, 2005; Brazeal \& Benoit, 2006). This theory posits, in essence, that "campaign discourse has only three functions ... acclaims, or positive statements; attacks, or negative statements; and defenses, or refutations of attacks" (Benoit et al., 2005, p. 361). Functional theory has been studied in diverse contexts such as press releases, debates, and television spots (Benoit \& Klyukovski, 2006; Cho \& Benoit, 2006; Stein, 2005). Significantly, the theory also states that news coverage of campaigns will specifically address two topics: the policies (or "issues") and character (or "image") of the candidates (Benoit et al., 2005, p. 361). This statement is germane to the goals of the present study, because it provides an analytical framework with which the findings of the present study may be interpreted. The present analysis will be conducted upon the assumption that this description of campaigns represents how "traditional" media (for example, newspaper and television) characterizes presidential campaigns. It should also be noted that the researchers found in a longitudinal study of print media's coverage of presidential campaigns that the news focused more on the image of the candidate than his or her issues (Benoit et al., 2005). These studies have also indicated that the incumbent acclaims his or her successes in debates more frequently than he or she attacks the challenger (p. 209), and that "ideals would ... form the basis for more acclaims than attacks" (p. 219). These findings have been replicated in others of its kind as well (Benoit \& Airne, 2005; Lee \& Benoit, 2005).

Jerit (2004) also examined rhetorical strategies of political candidates, finding that candidates tend to use arguments that evoke strong emotional appeals to fear, anxiety, and anger. These rhetorical strategies, utilized in election campaigns, functioned to mobilize support from their respective parties, as well as cater to the media's need for drama and excitement in campaign coverage: "Political elites who speak the language of emotion have a better chance of connecting with the electorate than those who do not" (Jerit, 2004, p. 566). This statement affirms Aristotle's (2007) claim that statements of pathos are one of the three major appeals of persuasion.

Based upon the research of Benoit and colleagues and Jerit, the present study hypothesizes that the candidate will use leadership utterances in presidential campaigns as a rhetorical strategy. Indeed, this study contends that presidential campaigns create rhetorical spaces to, as Hart and Daughton (2004) have stated, first persuade the audience to accept that choices must be made, and second, to accept that the candidate in question is the most appropriate choice. It is this hypothesis that will lead to the research questions that undergird this analysis.

\section{Research Questions}

Given the aforementioned findings, we may assume that the particular medium may have an effect upon the attitudes of the voter. Though the effects of YouTube upon the attitudes of its users remain outside of the purview of the present study, it aimed to discover the common characteristics and discrepancies between each presidential candidate's choices of leadership rhetoric as expressed through his or her video clips. This rhetoric was quantifiably measured through a content analytic approach of leadership- related utterances. Many of these video clips were provided on the YouChoose portion of YouTube.

The above review of the literature also suggests that the media and the political messages portrayed therein have their own discursive rules and effects. Though studies are beginning to emerge analyzing the effects of YouTube on civic engagement (McKinney \& Rill, 2009), there is little or no extant academic research about the presentation of political rhetoric in campaign videos on YouTube. Because the analysis and criticism of rhetoric lies at the intersection of language and politics (Wichelns, 2005), an analysis of the candidates' rhetorical 
strategies for leadership is warranted. Therefore, the following research questions guided this study:

RQ1: What are the most common characteristics of leadership delineated by the presidential candidates in their videos on YouTube?

RQ2: Which characteristics occur most frequently throughout the YouTube videos analyzed?

RQ3: What do the findings to the above questions indicate about (a) the format of each candidate's video clips, (b) the YouTube consumer who views these clips, and (c) the medium of YouTube itself?

Each of these issues will be addressed in subsequent sections of the study.

\section{Methods}

\section{Grounded Theory}

In order to answer the first research question, a grounded theory analysis was utilized to develop categories from which candidates' mentions of leadership traits would be coded for the content analysis. ${ }^{1}$ Corbin and Strauss (2008) have defined grounded theory as "a specific methodology developed ... for the purpose of building theory from data" (p. 1). This approach best facilitated the purpose of this study because Corbin and Strauss (2008) have characterized the research method as especially salient to interpreting "the regions of postmodern sensibility" (p. 9). Because the postmodern digital text of YouTube remains relatively untouched as a site of analysis, grounded theory may allow for a new research direction of the medium as a political text.

Because the objective of a qualitative analysis of the data is "to elicit meaning, gain understanding, and develop empirical knowledge" (p. 1), it is crucial for the researcher to accurately and openly analyze the artifact. To effectively utilize grounded theory, Strauss and Corbin (1998) recommended that the researcher use sampling, coding, and the writing of memos in his or her analysis (pp. 11-
12). The findings of the grounded theory analysis were yielded through an open coding approach, specifically through a "line-by-line analysis" of the discourse in each candidate's videos (Strauss \& Corbin, 1990, p. 72), in order to identify common themes. Following the open coding, the data was reassembled into categories, thus utilizing Corbin and Strauss's (2008) axial coding technique. These coding procedures ultimately resulted in categories composed of common characteristics and strategies utilized by the candidate throughout the videos.

\section{Content Analysis}

In order to answer the second research question, a content analysis was conducted once the grounded theory analysis was complete. A content analysis, as defined by Holsti, is "any technique for making inferences by objectively and systematically identifying specified characteristics of messages" (quoted in Riffe, Lacy, \& Fico, 2005, p. 23). This approach, "a nonobtrusive, nonreactive measurement technique" (Riffe et al., 2005, p. 38), was necessary to determine the frequency of the occurrence of each characteristic. The results of the content analysis will be the basis of the discussion section of the present study. The third research question will be answered by virtue of the findings of the aforementioned analyses.

\section{Texts Analyzed}

The selection of which candidates to include in this study was not made by the researcher but by YouTube; the only introduction video clips analyzed were posted by candidates that were originally included on the YouChoose section of the Web site. The introduction videos are notable because they were selected specifically by each candidate as the particular clips from which the American people would make its first impressions. Accordingly, these particular selections by each of the candidates was critical because the candidate would also be telling the voters indirectly what he or she perceived to be the most important points in his or her platform. The introduction videos were 
also selected for analysis because of their relevance to the new breed of YouTube politics; they demonstrate the intersection of digital media and politics.

Several of the candidates posted clips made exclusively for YouTube, though this assertion cannot be supported for all candidates. However, seven of the 16 candidates actually announced their candidacies on YouTube (Grove, 2008, p. 28). Sam Brownback began his introduction video with the words "Hello, YouTube!" and Duncan Hunter posted a low-resolution video that was made exclusively for dissemination on the Internet and not on high definition television. Hillary Clinton posted possible theme songs for her campaign on YouTube and asked supporters to vote for their choices, and hundreds of thousands responded (Grove, 2008, p. 29). In this respect, their uploaded introduction videos, though few in number compared to the distribution of other videos on the site, assume an important role in determining more about YouTube politics. Therefore, they were determined to be salient texts of analysis.

Each candidate's farewell video was also coded to complete the grounded theory portion of the study; endorsement videos were not included, unless they happened to be the same as the farewell video. When these were analyzed, some adjustments in the methodology became necessary: Because YouChoose did not specifically include farewell videos from the candidates that withdrew from the race, an exploration was conducted through the Web site to discover each candidate's farewell video. After extensive searching on the site using the qualifiers of the candidate's name and "drops out," "withdraws," "farewell," "speech," "concedes," and in some cases the date the candidate gave his or her withdrawal speech, some of the candidates had no video posted; these included Brownback, Hunter, and Fred Thompson. In fact, Brownback and Thompson's only farewell videos were brief public statements explaining their decision to withdraw in roughly 30 seconds. Brownback also had an introduction video posted on You-Choose, but a short time later he withdrew his name from the candidacy, and his video was promptly pulled as well. Thus, his introduction video was not coded.
The length of the video was also taken into consideration: Chris Dodd's farewell video included a portion of his speech, but was edited to a very short length. When Hillary Clinton withdrew her name from the candidacy on June 7, 2008, her campaign officially posted a 30-minute video of continuous coverage from CNN. Because the majority of the other candidates' farewell videos were only within the five to ten minute range, the inclusion of Clinton's full official video would have skewed the results and given undue emphasis to her comments. Therefore, another video of the same withdrawal speech was chosen for analysis that fit within the aforementioned time range (eight minutes). The content of the speech was not compromised by the shortened length of the clip.

Though only 30 video clips were analyzed for the study in total, they represented the entire population of introduction clips of the candidates listed on YouChoose and their respective farewell clips. These clips were by no means representative of the vast amount of political clips posted by each candidate's campaigns (Barack Obama's campaign, for instance, posted hundreds of official clips before he was elected president), but were determined to be sufficient for the aim and scope of the study.

Finally, only individual utterances were analyzed from candidates that were specifically germane to characteristics assumed to be indicative of their ability to lead the country. While some of the candidates specifically mentioned leadership as a skill, others only described the strength of their respective characters. Incidentally, Benoit's functional theory states that personal qualities, leadership ability, and ideals (values or principles) are all subtopics in that candidate's discourse about his or her character (Benoit \& Klyukovski, 2006). The methods employed here make assumptions closer to those of Just, Crigler, Alger, Cook, Kern, and West (1996), who state that character is more of a conglomeration constructed of issues, experience, and leadership ability. The present study analyzes the candidates' campaign messages in the race to be the party nominee (and ultimately president); therefore, the motives of each candidate for their words and videos are fundamental to their success. In the 
context of a presidential race, any utterance by a candidate will necessarily be rhetorical, used with the purpose to convince the voters of that image. Therefore, whenever a candidate made any utterance relating to character, it was interpreted to be a leadership trait. This is possible because each of the candidate's mentions of his or her own character is positive; were any of the mentions negative, they would likely be strategically made as the candidate's attempt at a detraction.

According to Pamela Benoit's (1997) typology of success strategies, the reason someone might use a detraction is because it "minimizes or downgrades the significance of the success" (p. 23). This would occur, in part, to show that the candidate's successes were incomplete; this is a strategy used mostly by incumbents, to garner support to be reelected and "finish what they started." Because there were no incumbents in this particular election, detractions are nonexistent in the videos, as well as negative mentions of character. Therefore, all references to character were favorable and thus interpreted to be leadership traits.

Likewise, the purpose of every video placed on YouTube by the candidate is rhetorical, or crafted with the intent to persuade the audience of the candidate's leadership abilities. Though not all character utterances may be related to leadership abilities in an everyday context, the uniqueness of the YouTube medium requires that each candidate's leadership motives dictate his or her character utterances. Each video appeared to focus primarily on the character of each candidate rather than his or her respective policies, thus moving the viewer to make his or her decision on who to support based on these character mentions rather than the more traditional policies and ideals of past elections. As a result, all occurrences of Benoit's concepts of personal qualities, leadership ability, and ideals were consolidated into leadership traits. Consequently, the majority of the candidates' arguments were interpreted to be a reference to their perception of a leadership characteristic as well.

Not all utterances were included where the candidate acclaimed his or her favorable characteristics or made promises about his or her future plans; only utterances that were not policy-driven were included. While these particular utterances may have fit the criteria for inclusion in this study, they were specific to policies that were often partisan without accurately reflecting that candidate's leadership characteristics. For example, if a candidate were to try to persuade the viewer to vote for him or her by saying he or she would reduce greenhouse gas emissions or build a wall along the Mexican border to discourage illegal immigration as president, it would not be coded as an utterance. For the purposes of this study, only leadership traits were analyzed that had the potential to be analyzed in different contexts.

\section{Coding Procedures}

When the content analysis was conducted, it became apparent that some utterances would need two or sometimes three separate codes. Since it was necessary that these utterances be mutually exclusive in order to facilitate replicability (Riffe et al., 2005), some adjustments to the methodology became necessary. If a candidate made an utterance that could be classified into several different categories, the coder would first examine the frequency of the traits. If the same trait was repeated multiple times along with a single other trait, the trait that was repeated the most would be coded for the same utterance multiple times.

In other circumstances, however, certain utterances would contain single mentions of more than one distinct trait. In order to eliminate doublecoding in these situations, precedence was given to the trait that was clearly emphasized more by the candidate. If the traits were emphasized equally, however, or if the coder could not determine which trait was emphasized, precedence would be given to the first trait mentioned in the utterance. This was decided upon because if the candidate did not specifically emphasize a leadership trait, by implication the most important trait would be spoken first. Though it is certainly not likely that this was the intent of the candidate in every circumstance, this decision was necessary in order to ensure uniformity of the coding. 


\section{Intercoder Reliability}

After the initial coding, a coder reliability test was then conducted using Cohen's $\mathrm{k}$ formula (Riffe et al., 2005, p. 151). Before this test was calculated, ten percent of the texts were coded by an assistant trained to ensure reliability regarding both the utterances in all 16 categories and the mutual exclusivity of each category. The test revealed that reliability for the categories was calculated at .90. According to Landis and Koch (1977), values of kappa between .61 and .80 indicate "substantial agreement," while values over .81 are considered "almost perfect" reliability between coders (p. 165). Reliability was thus considered acceptable for the study.

\section{Results}

Sixteen categories of common leadership traits emerged from the analysis: civic advocacy, virtue, courage, unification, persistence, crisis management, change, hard work, diplomacy, foresight, experience, service, patriotism, optimism, family, and hope. Each of these categories will be briefly delineated here with some illustrations from the clips. Each category and its respective frequency are illustrated in Table 1, while the categories by candidate and party are illustrated in Tables 2 and 3.

\section{Civic Advocacy}

A discursive trend emerged frequently among the candidates that they would continue to fight for their supporters, despite the fact that their campaign had come to an end. This was interpreted to indicate that the candidate was framing him or herself as a civic advocate. In Steinbeck's The Grapes of Wrath, the protagonist Tom Joad functions as an advocate to "the common man" when he makes the statement: "I'll be ever'where-wherever you look. Wherever they's a fight so hungry people can eat, I'll be there. Wherever there's a cop beatin' up a guy, I'll be there" (Steinbeck, 2002, p. 419). A similar promise was shared by many of the candidates to their supporters, thus ensuring their image as an advocate for the cause of the American public.
Table I. Overall Frequency of Leadership Mentions

\begin{tabular}{lc}
\hline Characteristic & Number of mentions \\
\hline Civic advocacy & $39(14 \%)$ \\
Virtue & $38(14 \%)$ \\
Courage & $35(12 \%)$ \\
Unification & $30(11 \%)$ \\
Persistence & $23(8 \%)$ \\
Crisis management & $20(7 \%)$ \\
Change & $15(5 \%)$ \\
Hard work & $13(5 \%)$ \\
Diplomacy & $12(4 \%)$ \\
Foresight & $11(4 \%)$ \\
Experience & $11(4 \%)$ \\
Service & $10(4 \%)$ \\
Patriotism & $7(2 \%)$ \\
Optimism & $7(2 \%)$ \\
Family & $6(2 \%)$ \\
Hope & $4(1 \%)$ \\
Total & $281(100 \%)$ \\
\hline
\end{tabular}

$\chi^{2}=1.5(d f=13), p>.05$ (n.s.).

Because of rounding, the numbers may not total one hundred percent.

In her farewell speech, for example, Hillary Clinton articulated this civic advocate trait: "We fought for all those who've lost jobs and health care, can't afford things, who've felt invisible to their president." Likewise, in his farewell speech, John Edwards presented himself as a crusading figure by reassuring his supporters that ending poverty is "the cause of my life." Fred Thompson's video clip likewise said that he was "ready to fight for us [and] our families." As a guiding principle, this trait was applied to utterances that mentioned fighting for something, standing up for something, or being perceived as a "hero." In his endorsement speech for John McCain, Rudy Giuliani, for example, twice referred to McCain as a hero.

In the same vein, "civic advocacy" was also coded as such when a candidate would speak of his or her "crusade" or "cause." In his farewell video, Tom Tancredo told how he "dedicated [his] public life to warning the nations of the perilous consequences of America's willingness to live with massive uncontrolled illegal immigration" and believed in the cause (or "crusade") so much that he decided to become a candidate for President "to force all presidential candidates to take a firm stand on the most critical domestic issue Amer- 
Table 2. Leadership Traits by Democratic Candidate

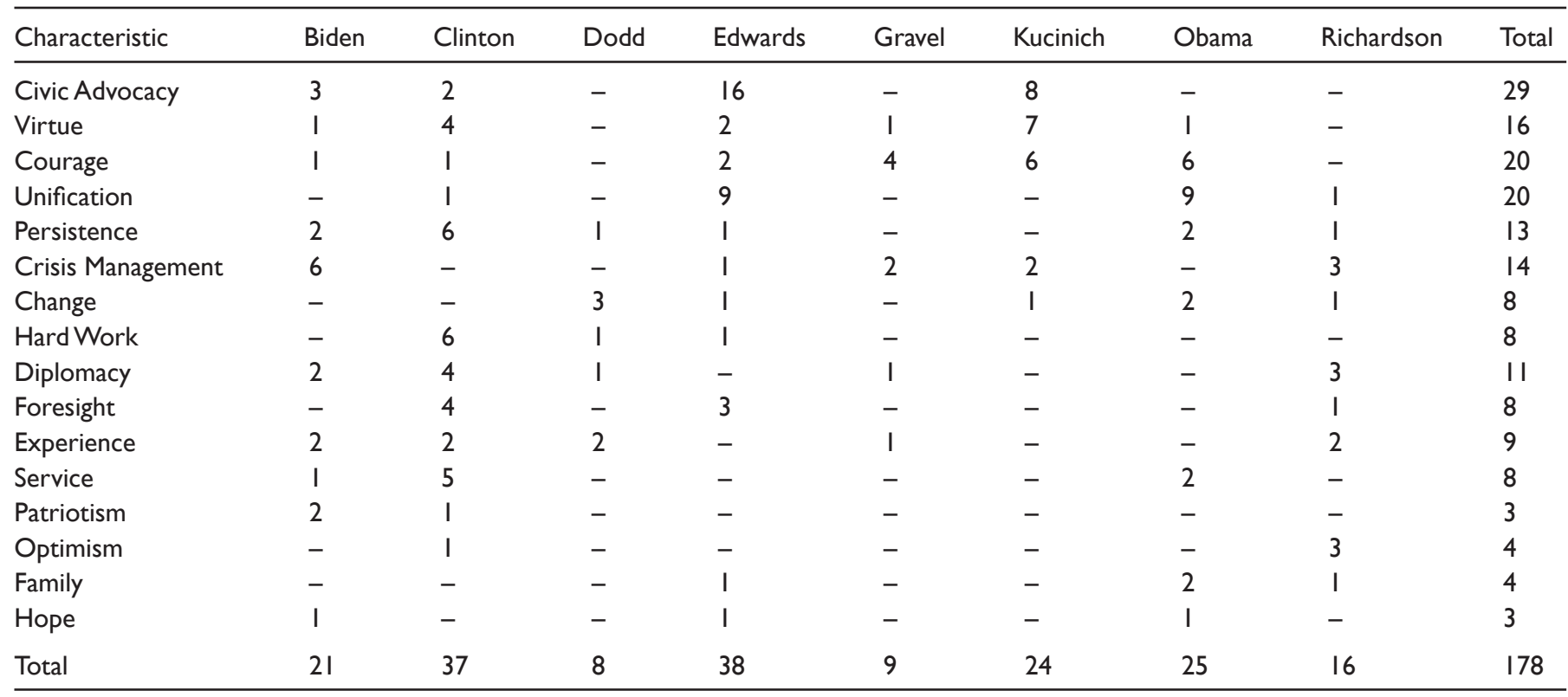

Table 3. Leadership Traits by Republican Candidate

\begin{tabular}{|c|c|c|c|c|c|c|c|c|c|}
\hline Characteristic & Brownback & Giuliani & Huckabee & McCain & Paul & Romney & Tancredo & Thompson & Total \\
\hline Virtue & - & 6 & 8 & 4 & - & - & - & 4 & 22 \\
\hline Unification & - & 2 & 4 & - & 1 & 1 & 1 & I & 10 \\
\hline Persistence & - & I & 4 & & 2 & 3 & - & - & 10 \\
\hline Crisis Management & - & 4 & - & - & - & 2 & - & - & 6 \\
\hline Hard Work & - & - & 3 & - & 2 & - & - & - & 5 \\
\hline Diplomacy & - & - & - & - & I & - & - & - & 1 \\
\hline Foresight & - & I & - & - & - & 1 & - & I & 3 \\
\hline Experience & - & I & - & 1 & - & - & - & - & 2 \\
\hline Service & - & - & 1 & - & - & - & - & I & 2 \\
\hline Patriotism & I & - & - & - & - & 3 & - & - & 4 \\
\hline Total & I & 16 & 31 & 6 & 10 & 17 & 7 & 15 & 103 \\
\hline
\end{tabular}

ica faces." Because the candidates' causes or crusades are implicitly understood to be their quest to accomplish something they in which they believe to bolster the people, each relevant utterance was coded as the civic advocacy trait.

\section{Courage}

Adhering to the traditional concept of courage, whenever a candidate spoke of showing bravery in the face of trying or perilous circumstances, it was coded as "courage." Republican candidate Mitt Romney gave an example of the traditional definition of courage when he said that he desired to see the next president not "retreat in the face of evil extremism." In addition to this concept of courage, this term was also applied to each candidate's statement that said he or she worked to overcome resistance or an environment that would otherwise hinder political progress. The narrative of Barack Obama's introduction video, for instance, states that his parents divorced when he was two years 
old and that he only saw his father once more before his father died. Likewise, when he was running for the Senate, he succeeded, despite being "outspent by a margin of six to one." Thompson's introduction video mentioned that he achieved the first college degree of his family, while Mike Huckabee stated that his mother-who was the oldest of seven kids - grew up in a house with dirt floors and outdoor toilets. These utterances were coded as courage because each enhanced the desirability of those candidates' future political achievements, and the courage that it took each of them to transcend trying circumstances. Likewise, an utterance was coded as courage whenever a candidate faced opposition from his or her own party when pursuing legislation that eventually proved to be the correct decision. These utterances are coded as courage because, by implication, each candidate had the courage to pursue his or her ideals against much resistance.

\section{Unification}

"Unification" was coded for promises that the candidates would bring both political parties together, as well as unite each party collectively to support its candidate. Obama, in particular, made use of this trait frequently, making the utterance nine times in only one video clip coded, and thus leading all of the candidates (see Table 2). Most of his claims of unification were made in statements like "there's not a liberal or conservative America, there is only the United States of America ... We are one people ... All of us pledging allegiance to the stars and stripes ... All of us defending the United States of America." Huckabee made similar assertions in his introduction speech by speaking about what he coined "horizontal politics": "Where everything is left or right, Republican or Democrat, Liberal or Conservative," but implored the American people to instead ask: "Which candidate will lift them to a higher place?" Ron Paul also spoke of unification when he told his supporters: "Let us all stick together in this great cause of liberty." These utterances were all coded as unification because they invited Americans to work together as a cohesive unit.
Unification was also coded for candidates who sacrificed their campaign ambitions for the good of the party. In Giuliani's endorsement of McCain, Giuliani said that they both believed in "building a stronger and broader Republican party," with the end goal of "break[ing] through the red state and blue state divide." Thus, though Giuliani had ceased his run for the nomination, he had projected his ambitions upon McCain for the good of the party. All unification utterances were coded as leadership traits because with each utterance, the candidate was committing to the American people that he or she could accomplish his or her objectives irrespective of ideological divisions.

\section{Virtue}

When a candidate's video clip delineated his or her favorable character traits or convictions regarding his or her personal values, those utterances were coded as "virtue." This code was chosen because virtue and character are often mutually associated (Hursthouse, 1999; Wilson, 1997). Giuliani, for example, said "a leader is ... a person of conviction" and is also committed "to what they believe is right for the future of their country." When endorsing McCain, he told of McCain's will, honor, integrity, and character. The narration to McCain's introduction clip was similar to Giuliani's words when it stated that McCain had "the integrity to deal with tough issues." Huckabee also endorsed McCain by saying he had "run an honorable campaign because he is an honorable man." Perhaps Bill Clinton's comment about Hillary Clinton best describes this aspect of virtue: "She is the best combination of mind and heart, of leadership ability, and the feel of the human consequences for the decisions that a leader makes." "Virtue" in this respect could also be synonymous with the term "moral compass." In other words, paraphrasing Clinton, the candidate understands the human consequences for his or her political decisions.

Moreover, when a candidate spoke of faith, it was also coded as virtue. Huckabee mentioned that he had "kept the faith" in both of his videos, and McCain said that faith sustained him while he had been a prisoner of war. Also, when a candidate 
made biblical references in his or her video clip, it was also coded as virtue: Huckabee acknowledged twice in his farewell speech that he was citing Biblical references, while Kucinich also referenced the Bible in his farewell speech twice-citing the same scripture as Huckabee about fighting the good fight, ${ }^{2}$ as well as the reference "the truth will set us free $^{\prime 3}$ - though he did not acknowledge that either comment was referencing the Bible. Ultimately, each biblical reference was coded as virtue because its utterance framed the candidate as a faithful participant in the Judeo-Christian tradition.

\section{Persistence}

"Persistence" was coded as any utterance where the candidate said he or she kept working, persevered, or continued to work. In short, the trait applied to a candidate who achieved successes while refusing to desist. Chris Dodd, in his introduction speech, stated that "it took [him] seven years to pass the Medical Leave Act." Obama was continuing to "work on issues that touch our life," while Clinton "[did not] give up," and "kept plugging away making progress day in and day out." Persistence was likely seen as desirable in a leader because it showed that he or she had the tenacity and determination to solve the challenges of the office.

\section{Diplomacy and Crisis Management}

While both "crisis management" and "diplomacy" were accurately depicted in certain utterances, a discrepancy arose when a candidate mentioned the war in Iraq; the term "diplomacy" was only applied to the end product of diplomatic negotiations, that is, when referring to restoring America's reputation, healing its image, and restoring peace. Additionally, the codes were not chosen from candidate utterances of that specific trait. For example, where one candidate said that he or she would focus on making allies and not enemies, it was coded as diplomacy. When a candidate claimed that he or she would end the war in Iraq and/or send the soldiers home, it was coded as crisis management. The difference in code occurred because while one candidate spoke of diplomatic relations, the other spoke specifically of undoing damage from a current crisis. In short, crisis management was coded as such when the candidate would mention the process of restoring order, such as ending the war, as opposed to the end product of diplomacy, such as the results of that restoration of order. Consequently, the candidate's use of the word "peace" was a crucial determiner of whether diplomacy or crisis management would be used; any mention of peace would garner a "diplomacy" classification. The "crisis management" utterances functioned rhetorically to portray a leader who was capable of making important decisions in difficult circumstances.

\section{Change}

Whenever a candidate spoke of change, using new policies, or giving the country a new direction, it was coded as "change." In his farewell speech, Dennis Kucinich mentioned that he entered the race "to bring a totally new perspective and direction to the office of president," while Ron Paul spoke repeatedly of "the changes of this revolution" referring to his presidential campaign. Change was coded as a leadership trait because in order to present meaningful change to a nation, the candidate would need innovative ideas and the power to achieve them. The discursive context was also essential with this code, because when a candidate mentioned that he or she would "change the state of the nation" it was coded as diplomacy, rather than change.

\section{Hard Work}

Because "work" is mentioned in multiple contexts by the candidates, "hard work" was coded only if a candidate stated that he or she "worked hard" to accomplish something. "Hard" is the semantic qualifier in this code, because its inclusion with "work" increases its rhetorical value and connotes that the candidate has achieved success through his or her own ambition and efforts. Though the utterance may have been coded as another trait, if it specifically mentioned hard work, it was coded as such. Huckabee, for example, explained that he "came from humble beginnings" then "worked hard." Dodd claimed that he 
"achieved results through hard work." Huckabee also appealed to those Americans who "work hard at their jobs," and stated that his campaign gave voice to these people, as did Edwards. Clinton invited her supporters to "work hard" for Obama's cause. Ultimately, "hard work" was coded as a leadership trait because it reinforces the capitalist ideals of a democratic society.

\section{Foresight}

Anytime a candidate spoke of the future of the political party, the American people, or the nation, it was coded as "foresight." This included Clinton's statement that as president she would "pursue a cleaner energy future," and the statement made when she withdrew her candidacy: "You'll always find me on the frontlines of democracy fighting for the future." Richardson invited all candidates to remain positive in their campaigns by speaking of the future rather than attacking each other. Edwards used his experiences of hearing children speak of their concern for the planet's future to elaborate upon his own platform. Giuliani outlined his similarities with McCain by stating that they both "share[d] a similar vision for the future of our party," and Romney foresaw the nation's "glorious future." In each of these utterances, the candidates demonstrated their assurance to the voters that they were mindful of the potential consequences of their decisions.

\section{Experience}

When a candidate mentioned that he or she was prepared or qualified to lead, the utterance was coded as "experience." Richardson's introduction video stated that he had "more international experience than just about anyone else in the 2008 field," while Biden had "a depth and breadth of experience in national security issues that no one else possess[ed]." The utterance was also coded as experience when a candidate referred to the duration of time that he or she had been in a leadership position. Biden spoke of visiting Iowa "since 1974" to garner the citizens' support for his candidacy, and indicated the amount of time he had worked to accomplish his goals in a leadership capacity. Bill Clinton mentioned in Hillary Clinton's introduction video that she had "spent a lifetime caring, working, and delivering" while she spoke of her service in the Senate in her farewell speech. The first utterance was coded as leadership because of her "lifetime" of leading and gathering experience, while the second utterance was coded as such because Clinton was telling America of her experience in leadership. These utterances indicated leadership aptitudes because they indicated to the voters that each candidate had had experience achieving results and, by implication, could continue to do so as the next president.

\section{Service}

"Service" utterances occurred when the candidates mentioned or implied that they worked among the people or had originally turned down the prospect of public office or lucrative jobs so that they could work among the people. In their respective introduction clips, Obama and Clinton both stressed the latter. The narration of Thompson's introduction video claimed that though Thompson was "not a professional politician ... [he had] a lifetime of service to our nation." This utterance is notable because Thompson's "lifetime of service" is what distinguished him from the bureaucratic DC politician stereotype.

Service was also coded for mentions of sacrifice by the candidates. Huckabee was the candidate with the most mentions of sacrifice; for example, he spoke of those who believed he belonged in the presidential race: "These are the people who gave me a voice over these past 14 months. It was their sacrifices ... those are the folks who gave me a voice, and I only pray to God that I could give them a voice." Biden made a similar statement: "So many of you have sacrificed for me, I feel so indebted to you." Although these utterances were made ostensibly to acclaim the hard work of the supporters, they likely only praised the candidate; by mentioning the sacrifices of unselfish people across America, the candidate acclaimed the importance of his or her candidacy as something for which it is worth sacrificing one's time and efforts. 


\section{Patriotism}

On occasion, the candidate would speak of his or her love for the nation or give an indication of its deep, personal meaning. For example, when Clinton concluded her farewell speech, she mentioned her "deep and abiding love for our country." When Biden announced his reason for running for president, he spoke similarly: "The reason to do this, the reason to make the effort ... is because we really, really, really do believe in this country." Likewise, Romney explained his motivation thus: "I entered this race because I love America." Romney also stated his belief in "the people of America, the source of this land's great strength." In a rare coded utterance from Sam Brownback, he exclaimed that he would leave the race "with great love for [his] country." Thus, according to the candidates, their love or belief in America motivated them to join the presidential race. This was interpreted as a leadership trait because it indicated that the candidate wanted to protect and help his or her country due to his or her patriotism.

\section{Optimism}

Both of Richardson's videos provided clear examples of the "optimism" utterance, with one stating that he led in optimism, and the other including the following statement: "Voters want to see us [the candidates] be positive about the country. . . ." Richardson then urged "all candidates to try to stay as positive as possible." Giuliani's introduction video also stated that he was an example of "optimistic leadership," as well as Huckabee's introduction video. Clinton stated that she shared Obama's optimism. These utterances were coded as leadership traits because the candidate was attempting to commend his or her character as favorable, and if the candidate's character is perceived as such, it is easier to garner support from the people (Brazeal \& Benoit, 2006).

\section{Family}

"Family" was coded for each utterance referencing the family of the candidate or making an appeal to families throughout the nation. Bill Richardson, for instance, stated that because he was withdrawing from the race, he would spend more time with his family. John Edwards mentioned his family immediately after officially announcing he was suspending his campaign. Mitt Romney said that his family and supporters had "given a great deal to get [him] to where [he has] a shot of becoming president." Obama asserted that his family was the "biggest blessing" of his life and "most important" to him. These utterances were coded as a leadership trait because they were often cited in the context of the candidate garnering support and strength from the family. By implication, a strong family surrounding the candidate would be an asset.

\section{Hope}

In the closing moments of his farewell speech, Romney gave an example of the "hope" trait with the statement that "America must always remain as it has always been, the hope of the Earth." Obama's candidacy provided to his supporters "a sense of hope in a time when things [were] not going that well." Biden received "great hope" from his supporters, while Edwards said his campaign would always be there to bring hope to the people of New Orleans after Hurricane Katrina. Hope is considered to be a leadership trait because, ideally, a politician should enhance the quality of life of his or her people, and hope is a manifestation of the desire to have that quality of life. The topic of hope is salient in political discourse; while Obama's 2004 speech about hope "redefine[d] the American dream," it also echoed allusions to hope that have permeated previous political speeches for decades (Rowland \& Jones, 2007, p. 433).

For the next phase of the research, a content analysis was conducted to measure the frequency of the aforementioned leadership traits. Each of the categories delineated in the analysis section was utilized to code the video clips. Because excerpts of the candidates' videos have already been provided to illustrate each category, only the frequencies will be reported in this section.

As demonstrated in Table 1, of the 16 leadership traits already mentioned, "civic advocacy" was the 
most common among the candidates, with 39 mentions, or 14 percent of total mentions. "Virtue" was next with 38 mentions (also 14\% of total mentions). "Courage" was next in frequency with 35 mentions $(12 \%)$, followed by "unification" with 30 mentions (11\%). "Persistence" occurred 23 times (8\%), while "crisis management" occurred 20 times (7\%). "Change" was next with 15 mentions (5\%), followed by "hard work" with 13 mentions (5\%), "diplomacy" with 12 mentions (4\%), and "foresight" and "experience" with 11 mentions each (4\%). "Service" was next with ten mentions $(4 \%)$, then "patriotism" with seven (2\%), and "optimism" also with seven. Finally, "family" had six occurrences $(2 \%)$, then "hope" had four (1\%). A chi-square statistical test was also performed on the results $\left(\chi^{2}=\right.$ $1.5[d f=13], p>.05$ [n.s.]).

\section{Discussion}

\section{Common Characteristics of Leadership}

An important factor in the candidates' concepts of leadership characteristics is the frequency of the utterances. Each of the candidates essentially chose the same leadership traits, but some mentioned certain traits more frequently. By implication, when a candidate frequently states that he or she exhibits certain leadership traits, he or she has more of that particular trait than the competition. Thus, the frequency of these mentions is important to the voter: The more one is mentioned, the more the voter will associate it with the candidate. Moreover, when the voter looks for that trait in other candidates, he or she will notice that they are lacking. For example, it appears that the common theme of the candidates is that of being an advocate for his or her constituents. It is likely that when the candidate is forming an exploratory committee, he or she is observing other candidates to see how they will frame their campaigns; accordingly, the candidate may try to "outdo" the competition.

It is possible that these leadership traits were also commonly mentioned by the candidates because they epitomize the essence of life in a democratic society. In this society, the people are ac- countable for deciding who will lead them; this culture also functions as a meritocracy (McNamee \& Miller, 2009), where the people desire that a leader should be rewarded who has overcome adverse circumstances and worked hard to achieve success. Because the mythic portrayal of the United States posits that the country is the "land of opportunity" (McNamee \& Miller, 2009, p. 1), it is important for those running for the presidency to take advantage of the mythic ideal of the American Dream. Accordingly, this ideal may have prompted the frequent utterances of traits like "persistence," "courage," and "hard work."

\section{The Frequency of the Characteristics}

The four traits that occurred more than 30 times each were "civic advocacy" (with 39 mentions, and $14 \%$ of total mentions), "virtue" (with 38 mentions, $13 \%$ of the total), "courage" (with 35 mentions, $12 \%$ of the total), and "unification" (with 30 mentions, $11 \%$ of the total). It appears from the results of the clips that the candidates chose to emphasize these particular traits more than others such as service or experience; it is possible that the candidates wanted to focus their attention on traits like courage and persistence to emphasize their embracing of the aforementioned American myth.

The most common leadership trait was the discursively created role of the candidate as an advocate for the American public. The frequency of this characteristic may have been indicative of the political atmosphere of the nation at the time of the election; as mentioned, certain candidates such as Biden, Edwards, and Kucinich presented themselves to their supporters as champions in the cause of justice, with Edwards and Kucinich specifically mentioning "justice" and "injustice." This is a significant trend because each Democratic candidate appeared to move one step beyond simply delineating their platforms, and to frame the Bush administration as corrupt, unjust, and unwilling to accept the plights of those citizens who suffer. To overcome this injustice, the candidate frames him or herself as a crusading hero, or a champion of rights that have been violated. This trait seems to be appealing to the candidates, because it was ad- 
opted by candidates in both political parties. However, when the trait was mentioned by candidates in the Republican Party, it appeared more frequently referring to the war (Giuliani), personal beliefs (Romney), illegal immigration (Tancredo), or families (Thompson). Even though the respective focuses of each candidate differed, the frequent appearance of this trait may suggest that the American people believe that they are in need of one who may fulfill the role of a hero.

Virtue, courage, and unification were, respectively, the second, third, and fourth most frequently mentioned leadership traits. These traits are likely popular because they enhance the teleological goal of the civic advocacy trait: the candidate should be perceived as a hero. As an example of this assertion, McCain was called a hero twice in Giuliani's exit video. Whenever a candidate would mention courage in the respect that he or she overcame a difficult situation, he or she was commending his or her ability to make correct decisions. As such, in order to effectively protect the American people, that candidate would need to be held accountable for his or her decisions and have the courage to make the right choice, even when the options available may not be desirable. Unification comes into the findings as an important trait because in order to achieve victories, the candidate needs to have the enthusiasm to bring together opposing factions. Thus, that candidate would want to assure the people that his or her ideals would transcend partisanship. Understanding these findings using Jerit's (2004) framework of political rhetoric used in campaigns, it is possible that each of these leadership traits may be used as an emotional appeal, thus producing a pathos within the audience. Though the appeals may not explicitly insight anger, fear, or anxiety within the audience, as Jerit suggested, each may incite a feeling of pleasure within the viewer. These emotions are all related to persuasive appeals using pathos (Aristotle, 2007).

\section{YouTube Politics}

Another important factor in the results of this study is the medium: it is possible that YouTube is facilitating the emergence of a new perception in politics - that of the postmodern constituency. As Grove (2008) stated, with YouTube, "politics is no longer bound by traditional barriers of time and space" (p. 28). Politics is no longer bound by barriers of convention either; YouTube is notorious for its short, amateur, and sometimes controversial videos. Moreover, this new breed of political videos is devoid of any unifying context or narrative within which it might be situated. YouChoose is a unique locus of meaning, because it presents a space, traditionally concerned with the grassroots ethos of YouTube (Burgess \& Green, 2009), that is replaced by the "elite discourse" (Simon \& Xenos, 2000, p. 363) characterized by influential politicians. More intriguing, however, is the fact that some of the candidates attempted to make the elite discourse appear framed as grassroots discourse. Because of the fragmented videos of the medium, the audience has perhaps become postmodern itself, thereby rejecting the overarching narratives of traditional media forms. Therefore, the candidates may try to accommodate those voters on their own terms. In March 2008, for example, Obama's campaign was posting two to three videos every day on You- Tube (Grove, 2008). These actions by the candidates also contrast the custom of traditional politics: Before, in order to hear the latest information from the presidential candidates, the citizen would need to be seated in front of the television at the appointed time, or reading a newspaper the day of the press release. With YouTube, and the Internet more generally, those criteria for receiving information appear to be shifting.

The Web site is a popular site of entertainment and politics for a generation that is wielding more power as voters now than ever before. It appears from the brevity of the uploaded clips and verbal cues exhibited in those clips that political candidates are adapting their messages to the medium. It is possible that when the candidates chose which video clips to post to personify their platforms, they chose more character-related clips to relate better to the postmodern YouTube generation. This may be, in part, why the most common traits in the analysis relate to the character of the candidate more than his or her political experience. 
Another implication of the medium is the unfiltered nature of YouTube. Unlike television political broadcasts, which have seemingly endless streams of media commentary about the words of each candidate, YouTube contains no official commentary by political pundits. This is significant when seen through the framework of Steeper's (1978) findings: During the 1976 political debates, Gerald Ford was asked a question about Communism, after which he made factually inaccurate comments. Steeper found that the sample of the American people in the study did not negatively adjust their opinions of Ford after he made the mistake; only after they heard the media's political commentary did they doubt the credibility of his statements. Steeper's findings demonstrate that media can have a dramatic impact on people's conclusions about the candidate. Likewise, Page (1996) suggested that the state of mediated deliberation has created a "punditocracy" where political commentary (particularly in print media or on cable news networks) may influence public opinion. Consequently, because of the absence of political commentary on YouTube, the users' conclusions about the candidates may have been different than if they had they only viewed another medium. Similar to the difference in the public's media-conditional perception of the Kennedy vs. Nixon debates (McLuhan, 1994), YouTube could one day present a paradigm shift in future political ads and videos.

\section{Conclusion and Implications}

The purpose of this study was threefold: (a) to discover which leadership utterances were used by the presidential candidates in their videos posted on YouChoose; (b) to discover which utterances were made most frequently by the candidates; and (c) to discover what these findings might indicate about the nature of politics on YouTube. The study yielded results that find leadership traits to be frequent in the presidential candidates' YouTube introduction and farewell video clips: The most frequently mentioned leadership traits were "civic advocacy," "courage," and "virtue." It appears from the results of this study that the leadership traits most frequently mentioned relate to the candidates' character more than their experience. This may be in part because of the medium of YouTube; it is possible that the candidates chose to use more character-driven utterances because they knew their speech or video would be placed on the site, and they desired to appeal to those users who frequent YouTube. As such, the medium has created a more fragmented approach to politics in general. In the more traditional medium of television, politics are presented more contextually: When the candidate speaks in a debate, for example, the viewer is given 90 minutes or more to hear the candidate's platform. On YouTube, however, the length of the video clip is crucial; because the time is limited, the candidate needs to choose the topics most salient to his or her campaign to include in the brief clip, while ensuring that they will also be interesting to the viewer. As Time magazine stated, "Web video is like a pop single: an attention-getting hook is important" (Poniewozik, 2006a, p. 74).

With the emergence of YouChoose, political candidates now find themselves as willing participants in a "buffet-style" variety of politics. In Internet politics before YouTube, potential voters would take the initiative to view each candidate's platform on his or her Web site; with YouChoose, however, those candidates are placed next to each other in the same forum for the consideration of the voter. This enables the casual voter, one who may be looking more for appearance, likability, or the character of the candidate rather than that candidate's basic policies, with a new political alternative, and thus endows that class of voter with more power than ever before. Incidentally, Habermas (1989) wrote that the emergence of a hedonistic consumer public endangered the critical debate that preserved the existence of a healthy public sphere. This same audience is also the target of YouChoose, upon which the citizens may make their decisions. This buffet-style of politics is providing a mediated forum for public deliberation, with the apparent aim to produce rational-critical debate among the public. However, the fact that this would occur on a medium previously known primarily for providing amusing amateur clips to a bored audience is somewhat paradoxical. 
In contrast to Barry's (2006) assertion about the active engagement that permeates Internet politics, YouTube Politics may actually promote passive engagement within the voter. Though navigating to a candidate's Web site is useful (Yoon \& Joseph, 2008) and more convenient than writing his or her campaign office for information or attending a political rally, the action is still made through the initiative of the user. However, with YouChoose, the user can simply view one Web site that literally places the videos of each candidate side by side. This allows for less of a commitment from the user than actively finding the official campaign Web site for each candidate. The user who visits the Web site of the candidate is likely already a supporter of that candidate; thus the medium only "reinforce[s] the partisan" (Lazersfeld et al., 1968, p. 101). However, the user who visits YouChoose to compare candidates may still be undecided or indifferent. Perhaps YouTube, like Lazersfeld et al.'s innovative political media study, will "activate ... the indifferent ... and convert ... the doubtful" (1968, p. 101). Lamentably, however, this may only occur to the voter who is already disposed to navigating the Internet, excluding others and thus widening the participation gap (Xenos \& Moy, 2007).

The present study also confirms, in part, various claims of Benoit's functional theory. Benoit and colleagues posited that presidential campaign discourse on YouTube, like traditional media coverage of presidential campaigns, would focus on two topics: issues and character (Benoit et al., 2005). Benoit (2003) also found that issues are more important to the majority of voters than character in voting in a presidential election. Though the present study elected to remove utterances about the candidates' policies from consideration, character utterances were mentioned more frequently in the candidates' discourse than political experience. The hierarchy of character claims over political experience claims here, though specifically not candidate policy, is still notable regarding Benoit's (2003) findings. Other research has indicated that utterances about policies and political experience may be coupled together in political discourse (Banwart, 2007). If experience and issues lack a clear distinction in the discourse of the campaign, the policy issues may be implicitly connected with political experience in the understanding of the constituents.

Though this study does not purport to analyze any variety of media effects, the implications of these findings are still intriguing: The discrepancies between Benoit's policy and character dichotomy and that of the present study may be due to the common perception of the YouTube audience as possessing a "garage-band attitude" (Becker, Grossman, Higgins, \& Romano, 2006, p. 14). YouTube has created out of its audience what may be called a postmodern constituency, which views political videos as decontextualized and self-contained. While not every candidate may hold this perception, it is ubiquitous enough to influence each candidate's choice of message, meaning that character utterances may resonate more with that postmodern audience than those of policy or experience.

Throughout the present study, the most significant limitation related to the ephemeral nature of the medium of analysis: YouTube does not allow its users to download each video. Moreover, the site will frequently pull videos without warning, and those videos will often never return to the site. This poses a new dilemma that is still only appearing as technology develops - that of the ephemeral text. An effort was made to extract the videos onto a computer using an external site, but unfortunately at least one video was lost, or reassigned to another section of the site; it is possible that more definitive versions of certain candidates' farewell speeches were available for a short time and then lost before they could be extracted for analysis. Though it is likely that were the full video available, the particular use of leadership traits would remain uniform with the partial video analyzed. However, the inability to code the full video for each of the candidates hindered the chance for each of the candidates to be given the equal amount of attention for analysis.

Because the focus of the present study resided solely upon the verbal utterances of the candidates, a research opportunity may be drawn from the visual images of the YouTube clips. In each clip presented, the candidate is communicating more than just verbally; he or she has chosen mu- 
sic, colors, or graphics to convey his or her message. For instance, Mike Gravel's introduction video is in stark black and white, and Hillary Clinton's and Rudy Giuliani's introduction videos are saturated with inspirational music. Though the analysis of these factors fell outside of the purview of the present study, these nonverbal elements of the videos could prove fruitful for future research opportunities.

\section{Notes}

1. The present study employed both qualitative and quantitative methods to answer the research questions. For the quantitative portion of the analysis, the statistics program SPSS was used to perform the chi-square test on the findings from the content analysis, and a Cohen's kappa was calculated and yielded an intercoder reliability of .90. If researchers desire to replicate the findings of the qualitative analysis, they may discover the archived information and codebook located at the Dataverse for the Journal of Information Technology E Politics: http://dvn.iq.harvard.edu/dvn/dv/jitp

2. "I have fought a good fight, I have finished my course, I have kept the faith" (2 Tim. 4:7, KJV).

3. "And ye shall know the truth and the truth shall make you free" (John 8:32, KJV).

\section{References}

Aristotle. (2007). On rhetoric: A theory of civic discourse, 2nd ed. (G. A. Kennedy, trans.). New York, NY: Oxford University Press.

Banwart, M. C. (2007). Constructing images in presidential primaries: An analysis of discourse strategies in the Dole and Bush Iowa straw poll speeches. Argumentation \& Advocacy, 43(2), 65-78.

Barry, A. (2006). On interactivity. In R. Hassan \& J. Thomas (Eds.), The new media theory reader (pp. 163187). New York, NY: Open University Press.

Becker, A., Grossman, B., Higgins, J. M., \& Romano, A. (2006). Big changes ahead. Broadcasting \& Cable, 136(41), 14-16.

Benoit, P. J. (1997). Telling the success story: Acclaiming and disclaiming discourse. Albany, NY: State University of New York Press.

Benoit, W. L. (2003). Topic of presidential campaign discourse and election outcome. Western Journal of Communication, 67, 97-112.
Benoit, W. L., \& Airne, D. (2005). A functional analysis of American vice presidential debates. Argumentation and Advocacy, 41, 225-236.

Benoit, W. L., \& Klyukovski, A. A. (2006). A functional analysis of 2004 Ukrainian presidential debates. Argumentation, 20, 209-225.

Benoit, W. L., Stein, K. A., \& Hansen, G. J. (2005). New York Times coverage of presidential campaigns. Journalism \& Mass Communication Quarterly, 82, 356-376.

Brazeal, L. M., \& Benoit, W. L. (2006). On the spot: A functional analysis of congressional television spots, 1980-2004. Communication Studies, 57, 401-420.

Burgess, J., \& Green, J. (2009). YouTube: Online video and participatory culture. Malden, MA: Polity Press.

Cho, S., \& Benoit, W. L. (2006). 2004 Presidential campaign messages: A functional analysis of press releases from President Bush and Senator Kerry. Public Relations Review, 32(1), 47-52.

Collins, C. (2006, October 13). It's a YouTube world ... we just surf in it. Christian Science Monitor, 11.

Corbin, J., \& Strauss, A. (2008). Basics of qualitative research (3rd ed.). Thousand Oaks, CA: Sage Publications.

Fernandez, R. (2006, December 9). Uploading American politics. The Washington Post, p. 19A.

Grossman, L. (2006, Nov. 13). YouTube: Best invention of the year. Time, 168, 64-65.

Grove, S. (2008). YouTube: The flattening of politics. Nieman Reports, 62(2), 28-29.

Habermas, J. (1989). The structural transformation of the public sphere: An inquiry into a category of bourgeois society (T. Burger, Trans.). Cambridge, MA: The MIT Press. (Original work published 1962).

Hart, R. P., \& Daughton, S. M. (2004). Modern rhetorical criticism (3rd ed.). New York, NY: Pearson.

Hursthouse, R. (1999). On virtue ethics. New York, NY: Oxford University Press.

Iyengar, S., \& Simon, A. (1993). News coverage of the Gulf Crisis and public opinion. Communication Research, 20, 365-383.

Jerit, J. (2004). Survival of the fittest: Rhetoric during the course of an election campaign. Political Psychology, $25,563-575$.

Just, M. R., Crigler, A. N., Alger, D. E., Cook, T. E., Kern, M., \& West, D. M. (1996). Crosstalk: Citizens, candidates, and the media in a presidential campaign. Chicago, IL: University of Chicago Press.

Landis, J. R., \& Koch, G. G. (1977). The measurement of observer agreement for categorical data. Biometrica, $33,159-174$. 
Lazersfeld, P. F., Berelson, B., \& Gaudet, H. (1968). The people's choice: How the voter makes up his mind in a presidential campaign (3rd ed.). New York, NY: Columbia University Press.

Lee, C., \& Benoit, W. L. (2005). A functional analysis of the 2002 Korean presidential debates. Asian Journal of Communication, 15, 115-132.

Mayer, J. D. (2008). American media politics in transition. New York, NY: McGraw-Hill.

McKeown, C. A., \& Plowman, K. D. (1999). Reaching publics on the Web during the 1996 presidential campaign. Journal of Public Relations Research, 11, 321-348.

McKinney, M. S., \& Rill, L. A. (2009). Not your parents' presidential debates: Examining the effects of the CNN/YouTube young citizens' civic engagement. Communication Studies, 60, 392-406.

McLuhan, H. M. (1994). Understanding media: The extensions of man. Cambridge, MA: MIT Press.

McNamee, S. J., \& Miller, R. K. (2009). The meritocracy myth. Lanham, MD: Rowman \& Littlefield.

Negroponte, N. (1995). Being digital. New York, NY: Knopf.

Overby, L. M., \& Barth, J. (2009). The media, the medium, and malaise: Assessing the effects of campaign media exposure with panel data. Mass Communication and Society, 12, 271-290.

Page, B. I. (1995). Speedy deliberation: Rejecting "1960s programs" as causes of the Los Angeles riots. Political Communication, 12, 245-261.

Page, B. I. (1996). Who deliberates? Mass media in modern democracy. Chicago, IL: University of Chicago Press.

Poniewozik, J. (2006a, November 6). When politics goes viral. Time, 168(19), 74.

Poniewozik, J. (2006b, December 25). The beast with a billion eyes. Time, 168(26), 63-64.

Riffe, D., Lacy, S., \& Fico, F. G. (2005). Analyzing media messages: Using quantitative content analysis in research (2nd ed.). Mahwah, NJ: Lawrence Erlbaum Associates.

Rowland, R. C., \& Jones, J. M. (2007). Recasting the American dream and American politics: Barack Obama's keynote address to the 2004 Democratic National Convention. Quarterly Journal of Speech, 93, 425-448.
Simon, A. F., \& Jerit, J. (2007). Toward a theory relating political discourse, media, and public opinion. Journal of Communication, 57, 254-271.

Simon, A. F., \& Xenos, M. (2000). Media framing and effective public deliberation. Political Communication, $17,363-376$.

Steeper, F. T. (1978). Public response to Gerald Ford's statements on Eastern Europe in the second debate. In G. F. Bishop, R. G. Meadow, \& M. Jackson-Beeck (Eds.), The presidential debates: Media, electoral, and policy perspectives (pp. 81-101). New York, NY: Praeger.

Stein, K. A. (2005). Success discourse in incumbent presidential television spots, 1956-2004. Public Relations Review, 31, 285-287.

Steinbeck, J. (2002). The grapes of wrath. New York, NY: Penguin Books.

Strauss, A. C., \& Corbin, J. M. (1990). Basics of qualitative research: Grounded theory procedures and techniques. Thousand Oaks, CA: Sage Publications, Inc.

Strauss, A. C., \& Corbin, J. M. (1998). Basics of qualitative research: Techniques and procedures for developing grounded theory (2nd ed.). Thousand Oaks, CA: Sage Publications, Inc.

Tan, E. (2007). Look out, '08 candidates: YouTube users are watching. Advertising Age, 78(19), 4.

Wichelns, H. A. (2005). The literary criticism of oratory. In C. R. Burgchardt (Ed.), Readings in rhetorical criticism (3rd ed.) (pp. 3-28). State College, PA: Strata Publishing. (Original work published 1925).

Wilson, J. Q. (1997). The moral sense. New York, NY: Free Press.

Xenos, M. (2008). New mediated deliberation: Blog and press coverage of the Alito nomination. Journal of Computer-Mediated Communication, 13, 485-503.

Xenos, M., \& Moy, P. (2007). Direct and differential effects on the Internet on political and civic engagement. Journal of Communication, 57, 704-718.

Yoon, D., \& Joseph, S. (2008). Comparisons of presidential election campaigns: A functional approach to the candidates' and their parties' Web sites and TV spots. Southwestern Mass Communication Journal, 24(1), 63-73. 